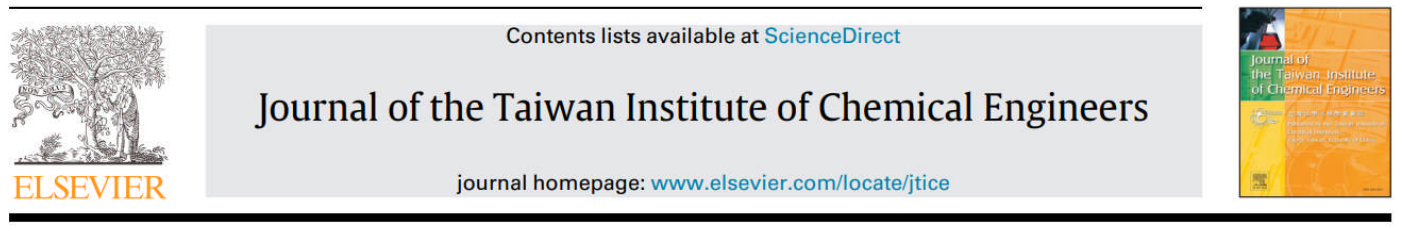

Enhancement of superoxide evolution by nickel-doped for the removal of organic pollutants and cyanobacteria

Haining Feng ${ }^{\mathrm{a}}$, Dongyu Xu ${ }^{\mathrm{a}, \mathrm{b}, \mathrm{c}}$, Qiuwen Wang ${ }^{\mathrm{a}, \mathrm{c}}$, Yilin Dong ${ }^{\mathrm{a}, \mathrm{c}}$, Guangming Zhang ${ }^{\mathrm{a}}$, Longyi Lv ${ }^{\mathrm{a}, \mathrm{c}}$, Zhijun Ren ${ }^{\mathrm{a}, \mathrm{b}, \mathrm{c}, *}$, Pengfei Wang ${ }^{\mathrm{a}, \mathrm{b}, \mathrm{c}, *}$, Luiza C. Campos ${ }^{\mathrm{d}}$

a School of Energy and Environmental Engineering, Hebei University of Technology, Tianjin 300401, China

${ }^{\mathrm{b} S}$ State Key Laboratory of Mineral Processing China

'Tianjin Key Laboratory of Clean Energy and Pollutant Control, Tianjin 300401, China

${ }^{\mathrm{d}}$ Department of Civil, Environmental and Geomatic Engineering, University College London, London WC1E 6BT, United Kingdom

\title{
Enhancement of Superoxide Evolution by Nickel-dop ed BiOCl for the Removal of Organic Pollutants and Cyanobacteria
}

Haining Feng a , Dongyu Xu ${ }^{\text {a,b,c }}$, Qiuwen Wang a,c ${ }^{\text {a }}$ Yilin Dong ${ }^{\text {a,c }}$, Guangming Zhang a , Longyi Lv ${ }^{\text {a,c }}$, Zhijun Ren ${ }^{\text {a,b,c* } * \text {, Pengfei Wang }}{ }^{\text {a,b,c* }}$, Luiza C. Campos ${ }^{\text {d }}$

${ }^{a}$ School of Energy and Environmental Engineering, Hebei University of Technology, Tianjin 300401, China

${ }^{\mathrm{b}}$ State Key Laboratory of Mineral Processing

c Tianjin Key Laboratory of Clean Energy and Pollutant Control, Tianjin 300401, China

${ }^{\mathrm{d}}$ Department of Civil, Environmental and Geomatic Engineering, University College London, London WC1E 6BT, United Kingdom

Zhijun Ren E-mail: renzhijun2003@126.com phone: $86+13102216950$

Pengfei Wang E-mail:pengfeiwang@hebut.edu.cn phone: 86+18222596134 


\section{Abstract}

Organic pollutants and cyanobacteria exist in water widely, which make significant impacts on human health so that appropriate methods are needed for their removal. In this work, Ni doped Bismuth oxychloride (BiOCl) photocatalysts were successfully synthesized by a simple hydrothermal method. The light absorption and charge carriers separation involved in superoxide $\left(\cdot \mathrm{O}_{2}^{-}\right)$generation can be optimized with the introduction of Ni element. And photocatalytic degradation experiments showed that the $9 \% \mathrm{Ni}-\mathrm{BiOCl}$ enhanced photodegradation activity of organic matter ( $\mathrm{Rh} \mathrm{B}$ and BPA) as well as $M$. aeruginosa. The degradation efficiency of $\mathrm{Ni-BiOCl}$ on the removal of $\mathrm{Rh} \mathrm{B}$ and $\mathrm{BPA}$ were approximately $34.99 \%$ and $57 \%$ higher than that of pristine $\mathrm{BiOCl}$. Furthermore, the algae inactivation was systematically studied by three-dimensional fluorescence spectrum. Results showed that $\cdot \mathrm{O}_{2}^{-}$acted an irreplaceable role among the experiment of photocatalytic algae removal, and the details were described as $\cdot \mathrm{O}_{2}{ }^{-}$and $\mathrm{h}^{+}$first destroyed the cell wall of $M$. aeruginosa, secondly inactivated the active fluorescent substances in the cell, and then catalyzed the oxidation of intracellular exudates such as chlorophyll and phycocyanin as inorganic substances. This study provides a multifunctional catalyst for controlling water pollution and environmental restoration.

Key words: Ni-doped $\mathrm{BiOCl}$; photocatalysis; superoxide; organic pollutants; Microcystis aeruginosa 


\section{Introduction}

Trace organic pollutants and cyanobacteria blooms in water have attracted more and more attention for their health hazards and threats to the ecological environment [1-2]. Recently, a lot of treatment ways have been explored to address this issue such as adsorption, ozonation, chlorination, ultrasound and photocatalysis [3-6]. Metals/Minerals-Incorporated materials are versatile and cost-competitive for removing organic and inorganic pollutants from waters, different industrial applications have been recently reported [7-8]. However photocatalytic technology, due to the high efficiency and no secondary pollution, has been regarded as an important pollution control technology for environmental remediation [9]. Generally, the highly active reactive oxygen species (ROS) in photocatalytic process, including hydroxyl radical $(\cdot \mathrm{OH})$, singlet oxygen $\left({ }^{1} \mathrm{O}_{2}\right)$, superoxide anion radical $\left(\cdot \mathrm{O}_{2}^{-}\right)$and hydrogen peroxide $\left(\mathrm{H}_{2} \mathrm{O}_{2}\right)$, play an important role on pollutant removal [10]. In recent years, various of photocatalysts, such as $\mathrm{TiO}_{2}, \mathrm{ZnO}, \mathrm{BiOX}$ and carbon nanotubes, have been employed for ROS generation and pollutant degradation [11-13]. However, the pristine photocatalysts have always been restricted by the low photocatalytic efficiency.

Researches showed that $\mathrm{BiOCl}$ possesses a unique layered structure, in which a $\left[\mathrm{Bi}_{2} \mathrm{O}_{2}\right]^{2+}$ layer is sandwiched by two $\left[\mathrm{Cl}_{2}\right]^{2-}$ layers in the crystal perpendicular to the c-axis of the unit cell so that each $\mathrm{Bi}^{3+}$ ion is coordinated to four oxide ions from one layer and five chloride ions from the next layer [14-15]. This layered structure is conducive to the separation of electron holes [16]. Therefore, $\mathrm{BiOCl}$ is adopted as a 
promising bismuth-based catalyst. And lots of subsequent attempts have been made to enhance the activity of $\mathrm{BiOCl}$, such as elemental doping, creation of vacancies, and construction of heterojunctions [17-19]. Among them, doping can enhance the photocatalytic performance of the catalyst through reducing the band gap energy of the catalytic material, expanding the light absorption range, and increasing oxygen vacancies [20-22]. What worth mentioning is that the crystal structure remain unchanged [23-24]. Based on recent reports, nickel (Ni) is a magnetic metal element with excellent electrical conductivity and electron-capturing ability [25]. Thus, we propose a guess that $\mathrm{Ni}$ could be another promising element to improve the activity of $\mathrm{BiOCl}$ by doping. And Ni-modified $\mathrm{BiOCl}$ has not been reported for photocatalytic degradation. What is more, previous reports either focused on the degradation of harmful organics such as phenol, tetracycline and ciprofloxacin or the inactivation of cyanobacteria alone [26-29]. However, the studies of versatility of catalysts that can simultaneously degrade organics and cyanobacteria are rare. To find a multifunctional catalysts, we tried to ameliorate the activity of $\mathrm{BiOCl}$ via $\mathrm{Ni}$ doping, and this study may provide an efficient example for simultaneously removal organic pollutants and cyanobacteria in waste water.

In this present work, we first synthesized a layered $\mathrm{Ni}-\mathrm{BiOCl}$ nanosheet by an uncomplicated one-step hydrothermal synthesis way. $\mathrm{Ni}-\mathrm{BiOCl}$ and $\mathrm{BiOCl}$ were characterized from the aspects of morphology, electrochemical performance, light absorption performance, charge separation and charge injection to evaluate the role of doped Ni element. The organic pollutants Rhodamine B (Rh B) and bisphenol A (BPA) as well as Microcystis aeruginosa (M. aeruginosa), the dominant algal species caused blooms, were applied as target object to test the photodegradability of the prepared samples. In consideration of environmental restoration and energy utilization, a series 
of single-factor inactivation experiments of $M$. aeruginosa was conducted to evaluate the photocatalytic inactivation activity and define optimal reaction conditions. The overall goal of this study is to explore multifunctional catalyst to solve the perplex of environmental harm caused by organic pollutants and M. aeruginosa.

\section{Experiment section}

\subsection{Preparation of Ni-BiOCl photocatalysts}

Pure and Ni-doped bismuth oxychloride $(\mathrm{BiOCl})$ were prepared by simple hydrothermal method. In a representative preparation process of $\mathrm{Ni}-\mathrm{BiOCl}, 1.455 \mathrm{~g}$ of $\mathrm{Bi}\left(\mathrm{NO}_{3}\right)_{3} \cdot 5 \mathrm{H}_{2} \mathrm{O}(3 \mathrm{mmol})$ and $0.2237 \mathrm{~g}$ of $\mathrm{KCl}(3 \mathrm{mmol})$ were dispersed in $16 \mathrm{~mL}$ ethylene glycol (EG) and make the same three copies. Then $0.0728 \mathrm{~g}, 0.1310 \mathrm{~g}$, and $0.1892 \mathrm{~g} \mathrm{NiCl}_{2} \cdot 6 \mathrm{H}_{2} \mathrm{O}$ were added into to the three mixture respectively and magnetically stirred into a uniform suspension to guarantee the medicine was dissolved completely. Then, the mixture was poured into a $100 \mathrm{~mL}$ autoclave and heated at $160{ }^{\circ} \mathrm{C}$ for $12 \mathrm{~h}$. After natural cooling, the solid products were gathered through centrifugal separation and rinsed with deionized water and absolute ethanol for three times respectively to remove the surface impurities. In the end, after vacuum drying at $60{ }^{\circ} \mathrm{C}$ for 12 hours, the characteristics were evaluated, and products obtained represented as $\mathrm{x} \% \mathrm{Ni}-\mathrm{BiOCl}$ (where $\mathrm{x}$ presents the mass content, and $\mathrm{x}=5,9,13$ ). For comparison, the preparation of $\mathrm{BiOCl}$ under the same conditions without using $\mathrm{NiCl}_{2} \cdot 6 \mathrm{H}_{2} \mathrm{O}$.

\subsection{Physicochemical characterization}

The X-ray diffraction (XRD) curves of the prepared samples were measured by D8 Discover diffract meter (Germany) with a nickel-filtered $\mathrm{Cu}-\mathrm{K} \alpha$ radiation source (= 
1.54056̊̊). X-ray photoelectron spectrum (XPS) was measured via a ESCALAB 250Xi (Germany) electron spectrometer with $150 \mathrm{~W}$ Al-K $\alpha$ X-ray sources. Fourier transform infrared spectrometry (FTIR) spectrum was noted for the products on an Thermo NicoletiS5 carried with a liquid-nitrogen-cooled MCT detector. Transmission electron microscopy (TEM) and the HRTEM were gathered on a Talos F200S electron microscope (FEI Co). The photoluminescence (PL) spectrometry for prepared products were tested on a PL3-22 (HORIBA Co) photoluminescence detector. The Shimadzu U-3900H spectrophotometer was used to gather the ultraviolet-visible spectroscopy (UV-vis). Using $\mathrm{BaSO}_{4}$ as a standard reference sample, the light reflectance of the product was measured by an instrument. The electron spin resonance (ESR) and the electron paramagnetic resonance (EPR) signals of radicals spin-trapped by spin-trap reagent 5,5-dimethyl-1-pyrroline n-oxide (DMPO) were analyzed on a Bruker A300 spectrometer. Three-dimensional fluorescence spectrum of the cell dissolved organic matter (DOM) was examined on a HITACHI F-4600 spectrometer.

\subsection{Electrochemical characterization}

A home-made three-electrode system was employed to realize the electrochemical test, and the counter electrode was $\mathrm{Ag} / \mathrm{AgCl}(\mathrm{KCl}, 3 \mathrm{M})$ while the reference electrode was Pt wire. The specimen on conductive glass (FTO) was considered as the working electrode for photocurrent measurement plots examination and electrochemical impedance spectroscopy (EIS) measurements as well as the Mott-Schottky (MS). The obtained voltage vs. $\mathrm{Ag} / \mathrm{AgCl}$ was alternated to reversible hydrogen electrode (RHE) scope via the Nernst formula: $E_{R H E}=E_{A g / A g C l}+0.197+0.059 p H$. EIS test was operated by using an alternating current (AC) with a voltage of $5 \mathrm{mV}$ and the 
frequency fluctuated between $10^{-2}$ and $10^{6} \mathrm{~Hz}$. The all tests were carried on a electrochemical workstation (CHI 600E, Chenhua Co, China). The characterization and experiments use the same light source.

\subsection{Rhodamine B and Photodegradation of Bisphenol A}

A $300 \mathrm{~W}$ Xe lamp (CEL-HXF300, Zhongjiao Instrument Co, Chain) with a $420 \mathrm{~nm}$ cut-off filter was used as the light source at room temperature to study the photodegradability of the catalyst. $50 \mathrm{mg}$ catalyst was dispersed in the prepared 100 $\mathrm{mL} 10 \mathrm{mg} \mathrm{L}^{-1} \mathrm{Rh} \mathrm{B}$ solution. The speed of the magnetic stirrer was set to $800 \mathrm{r} \mathrm{min}^{-1}$ to ensure that the catalyst was evenly suspended in the Rh B solution. It was subjected to dark conditions for 15 minutes to gain an adsorption/desorption equilibrium and then the suspension was placed under the Xe lamp. At regular intervals, $4 \mathrm{~mL}$ samples were taken and centrifuged (TG16-WS, Hunan Xiangyi Co, Chain) for 5 minutes at a speed of $10000 \mathrm{r} \mathrm{min}^{-1}$, and the measurement for the samples absorbance value were decided by a UV spectrophotometer (752, Shanghai Jinghua Co, Chain) at a wavelength of $532 \mathrm{~nm}$. According to Lambert-Beer law, the change in $\mathrm{Rh} \mathrm{B}$ concentration could be represented by corresponding absorbance $\left(\mathrm{C}_{t} / \mathrm{C}_{0}\right)$ [30]. The degradation process of $10 \mathrm{mg} \mathrm{L}^{-1} \mathrm{BPA}$ is the same as that of $\mathrm{Rh} \mathrm{B}$. The wavelength measured by UV spectrophotometer is $278 \mathrm{~nm}$.

\subsection{Algae inhibition experiment}

The experiment of photocatalytic deactivation of $M$. aeruginosa was performed with a homemade photochemical reactor. The reaction device contained multiple accessories, such as a magnetic stirrer, a double-layer beaker, and a cooling system which can keep the reaction temperature stable. The intensity range of the light source 
was adjusted around 55-85 klux. Prepare a concentration of algae with a concentration of $2.6 \times 10^{6}$ cells $\mathrm{mL}^{-1}$, also it could be modulated to other concentrations, while the catalyst was added at a rate of $0.02-0.10 \mathrm{~g}$ to $150 \mathrm{ml}$ of the reaction solution. At a given time of 10 minutes, the algae fluid were sampled and immediately placed on hemocytometer for statistics. Meanwhile, at predetermined time of 20 minutes after turn on the light, the samples were processed for three-dimensional fluorescence scanning.

\section{Results and discussion}

\subsection{Characterizations of the photocatalysts}
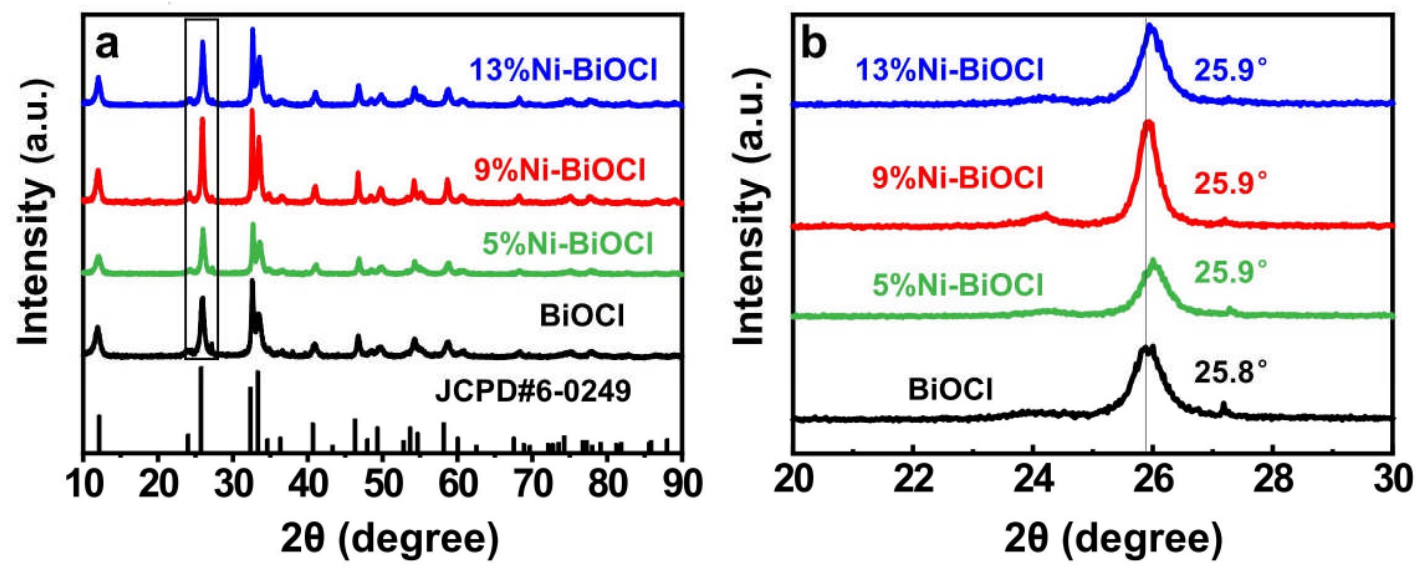

Fig. 1. (a) XRD and (b) Partial XRD patterns of samples.

The phase structure and crystallinity of $\mathrm{BiOCl}$ and $\mathrm{Ni}-\mathrm{BiOCl}$ were researched by X-ray diffraction (XRD) patterns (Fig. 1a). The range of diffraction peaks created by $\mathrm{Ni}-\mathrm{BiOCl}$ correspond with the characteristic peaks of the standard calorie in $\mathrm{BiOCl}$ (JCPDS\#06-0249) [31]. In addition, the results showed that all the diffraction peaks moved about $0.1^{\circ}$ to a large angle (Fig. 1b), which indicated that the lattice 
parameters of $\mathrm{Ni}$-doped $\mathrm{BiOCl}$ were smaller than the pure one [10]. Since the radius of $\mathrm{Ni}^{2+}(0.069 \mathrm{~nm})$ is smaller than the that of $\mathrm{Bi}^{3+}(0.117 \mathrm{~nm})$, it can be considered that the change in the crystal lattice and the movement of the peaks for a high angle were attributed to the reason that $\mathrm{Ni}$ was doped into the main crystal successfully [32-33]. Fourier transform infrared spectroscopy (FTIR) also proved that $\mathrm{Ni-BiOCl}$ was successfully prepared (Fig. S1). Furthermore, the doping of $\mathrm{Ni}^{2+}$ may eliminate the electrostatic balance, and this should be rebalanced (managed) by forming vacancies, which will be discussed in detail later [34].
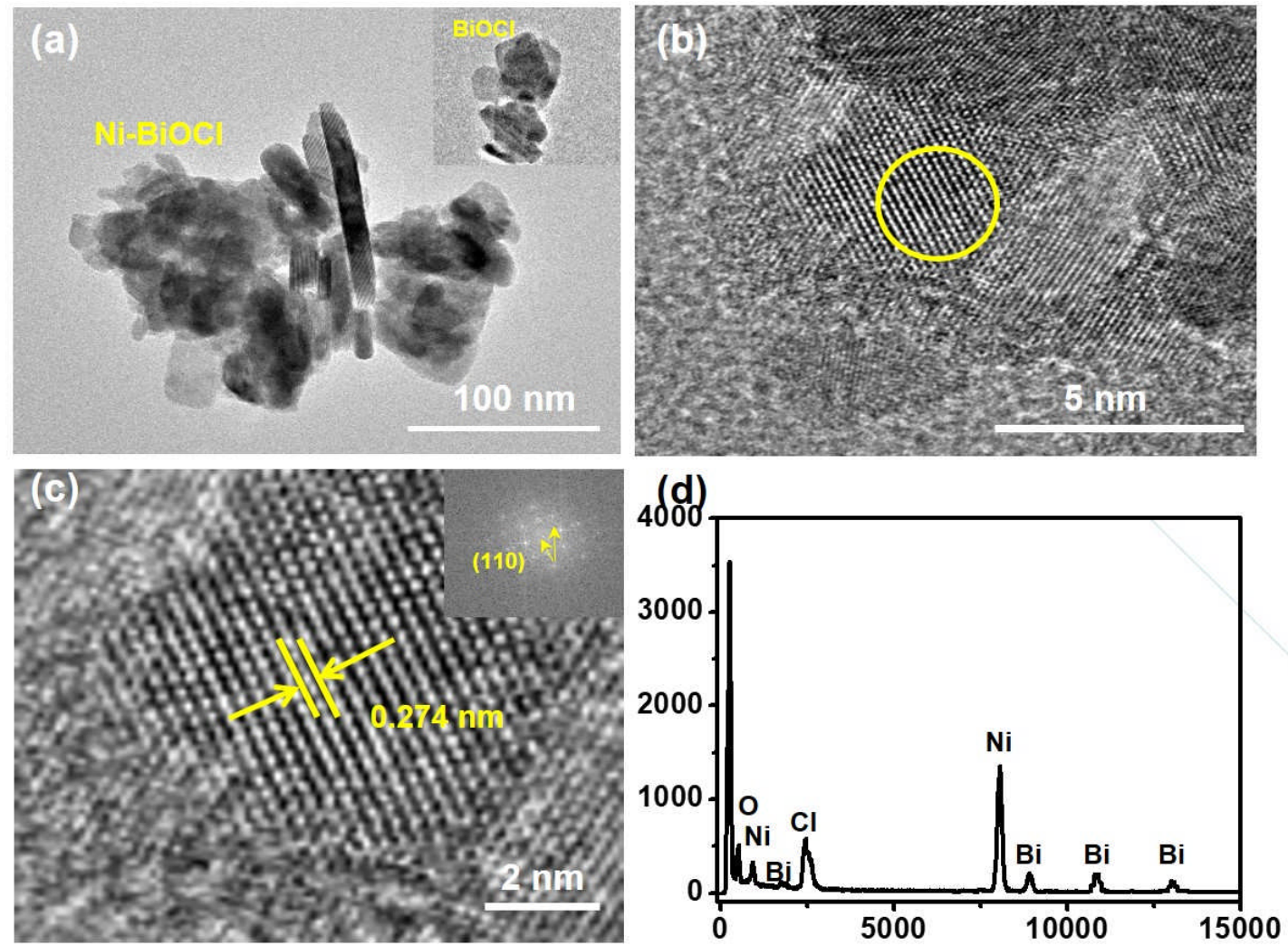

Fig. 2. (a) TEM images of $9 \% \mathrm{Ni}-\mathrm{BiOCl}$ and $\mathrm{BiOCl}$; (b) HRTEM; (c) enlarged HRTEM and the corresponding electron diffraction pattern (insert); and (d) EDS of 9\% Ni-BiOCl. 
TEM was measured to analyze the topography and internal structure of the samples.

As Fig. 2a shown, $\mathrm{BiOCl}$ and $\mathrm{Ni}-\mathrm{BiOCl}$ are two-dimensional sheet-like nanostructures and a relatively smooth surface can be observed. In Fig. 2b, the lattice fringes are distinct and consecutive, revealing that the $\mathrm{Ni}-\mathrm{BiOCl}$ nanoflakes have good crystallinity. As shown in Fig. 2c, the space of the lattice fringes is determined as $0.274 \mathrm{~nm}$, which is relevant to (110) flat of $\mathrm{BiOCl}$ and the built-in graph also can confirm this conclusion [35]. Apart from this, the elemental content of Ni-BiOCl was also studied via EDS. As the Fig. $2 \mathrm{~d}$ shown, the $\mathrm{Bi}, \mathrm{Ni}, \mathrm{Cl}$, and $\mathrm{O}$ peaks generated by the $2 \mathrm{D}$ nanosheets verify the existence of $\mathrm{Ni}$ in the prepared product. Ni lattice was not observed in HRTEM, which meant that $\mathrm{Ni}$ element were doped into the $\mathrm{BiOCl}$ lattice opportunely, which was consistent with the Raman spectra (Fig. S2). 

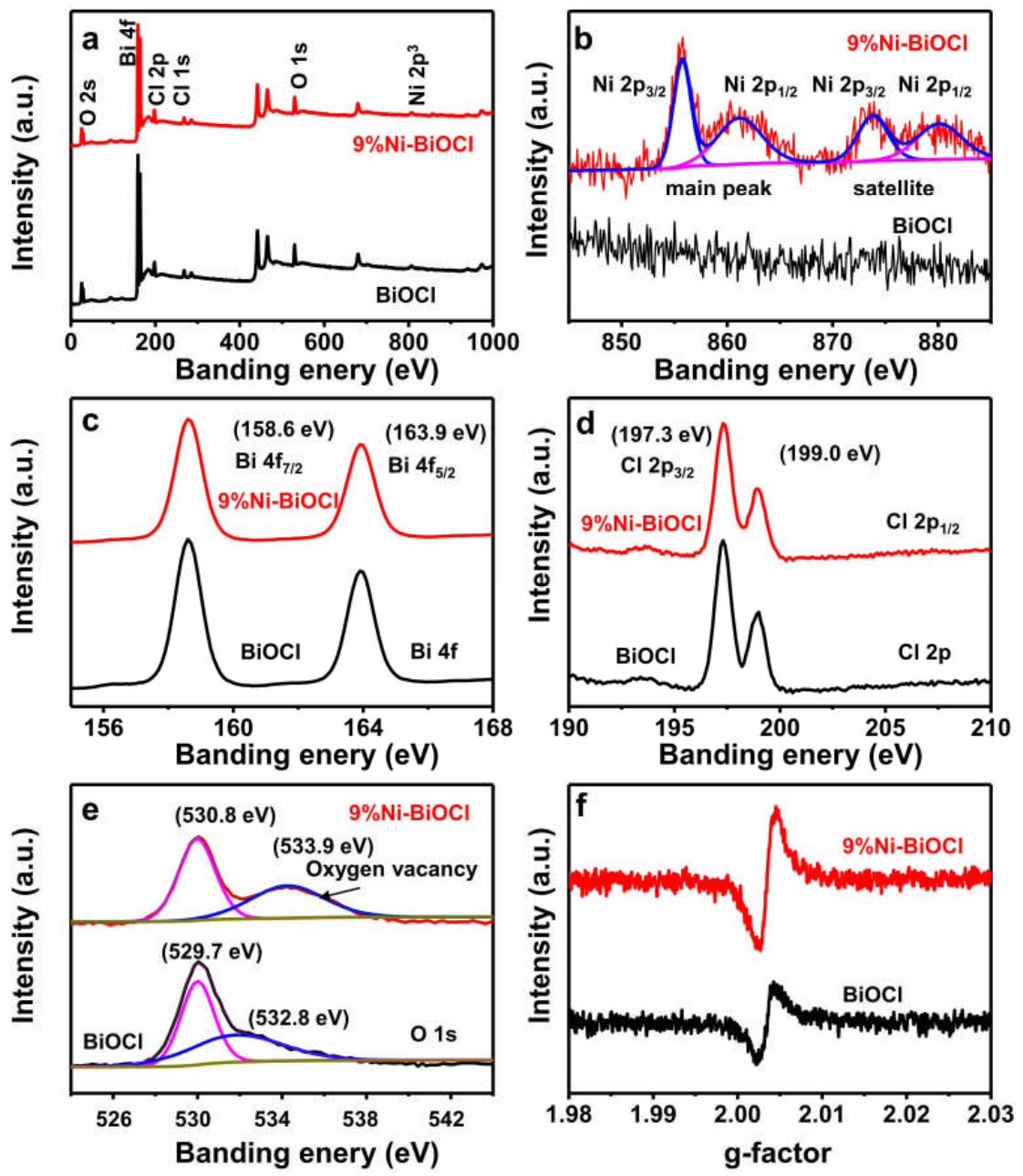

Fig. 3. (a) XPS full spectrum; (b) Ni 2p; (c) Bi 4f; (d) $\mathrm{Cl} 2 \mathrm{p}$; (e) $\mathrm{O}$ 1s and (f) EPR spectra of sample.

To grasp the surface elementary composition, element valence and the electronic interaction of $\mathrm{BiOCl}$ and $\mathrm{Ni}-\mathrm{BiOCl}$ samples, XPS was measured. As shown in Fig.3a, the prepared catalyst contains four elements: $\mathrm{Bi}, \mathrm{O}, \mathrm{Cl}$ and $\mathrm{Ni}$, which was the same with the EDS characterization results. As shown in Fig. 3b, Ni 2p spectra of Ni-BiOCl could be segmented into four characteristic peaks at $855.7 \mathrm{eV}, 861.3 \mathrm{eV}, 873.6 \mathrm{eV}$ and $879.8 \mathrm{eV}$, which represent main peak $\mathrm{Ni} 2 \mathrm{p}_{3 / 2}$ and $\mathrm{Ni} 2 \mathrm{p}_{1 / 2}$ as well as the satellite peak $\mathrm{Ni} 2 \mathrm{p}_{3 / 2}$ and $\mathrm{Ni} 2 \mathrm{p}_{1 / 2}$, demonstrating that $\mathrm{Ni}$ was combined with $\mathrm{O}$ to form $\mathrm{Ni}-\mathrm{O}$ bonds existing in Ni-BiOCl [34]. In Fig. 3c, two strong peaks of $158.6 \mathrm{eV}$ and $163.9 \mathrm{eV}$ 
were designated as $\mathrm{Bi} 4 \mathrm{f}_{7 / 2}$ and $\mathrm{Bi} 4 \mathrm{f}_{5 / 2}$ of $\mathrm{Bi} 4 \mathrm{f}$, demonstrating that $\mathrm{Bi}^{3+}$ as a form of Bi existed in both $\mathrm{BiOCl}$ and $\mathrm{Ni}-\mathrm{BiOCl}$ [36]. As described by $\mathrm{XRD}$ analysis, the lattice parameters of $\mathrm{Ni}-\mathrm{BiOCl}$ are decreased via adulteration $\mathrm{Ni}$, showing that the $\mathrm{Bi}$ atoms in $\mathrm{Ni}-\mathrm{BiOCl}$ are closer to $\mathrm{O}$ atoms. Fig. $3 \mathrm{~d}$ shows that the $\mathrm{Cl} 2 \mathrm{p}$ on both sides of $198.1 \mathrm{eV}$ can be allocated to $\mathrm{Cl} 2 \mathrm{p}_{1 / 2}(197.3 \mathrm{eV})$ and $\mathrm{Cl} 2 \mathrm{p}_{3 / 2}(199.0 \mathrm{eV})$ energy levels, which are characteristic peaks of $\mathrm{Cl}^{-}[37]$. O 1s spectrum indicates that (Fig. 3e), the peak at $529.7 \mathrm{eV}$ is part of the $\mathrm{Bi}-\mathrm{O}$ bond from $\mathrm{O}^{2-}$. And the additional peak at $532.8 \mathrm{eV}$ comes from the oxygen vacancies in $\mathrm{BiOCl}$ and $9 \% \mathrm{Ni}-\mathrm{BiOCl}$ [38]. Compared with $\mathrm{BiOCl}$, the peaks of the $\mathrm{Ni}-\mathrm{BiOCl}$ show obvious red-shifted, and the concentration of surface oxygen vacancies increase after $\mathrm{Ni}$ doping. To further confirm this result, EPR was tested. As shown in Fig. 3f, there were obvious EPR signal peaks for both the samples, which could be assigned to paramagnetic oxygen vacancies [39]. It is interesting that compared with $\mathrm{BiOCl}$ the characteristic peak intensity of $9 \% \mathrm{Ni}-\mathrm{BiOCl}$ is stronger, which means that the content of oxygen vacancies increases, and this is accord with the results of XPS analysis. Amusingly, the oxygen vacancies are able to capture or combine electrons to generate paramagnetic resonance. For $\mathrm{Ni}-\mathrm{BiOCl}$, the more oxygen vacancies, the shorter the average moving distance of the electrons, which makes it easier for the oxygen vacancies to combine with the electrons to form a resonance exciton to separate the electron-hole pairs [40]. Therefore, the photocatalytic activity was greatly improved.

\subsection{Photocatalytic ROS generation performance}



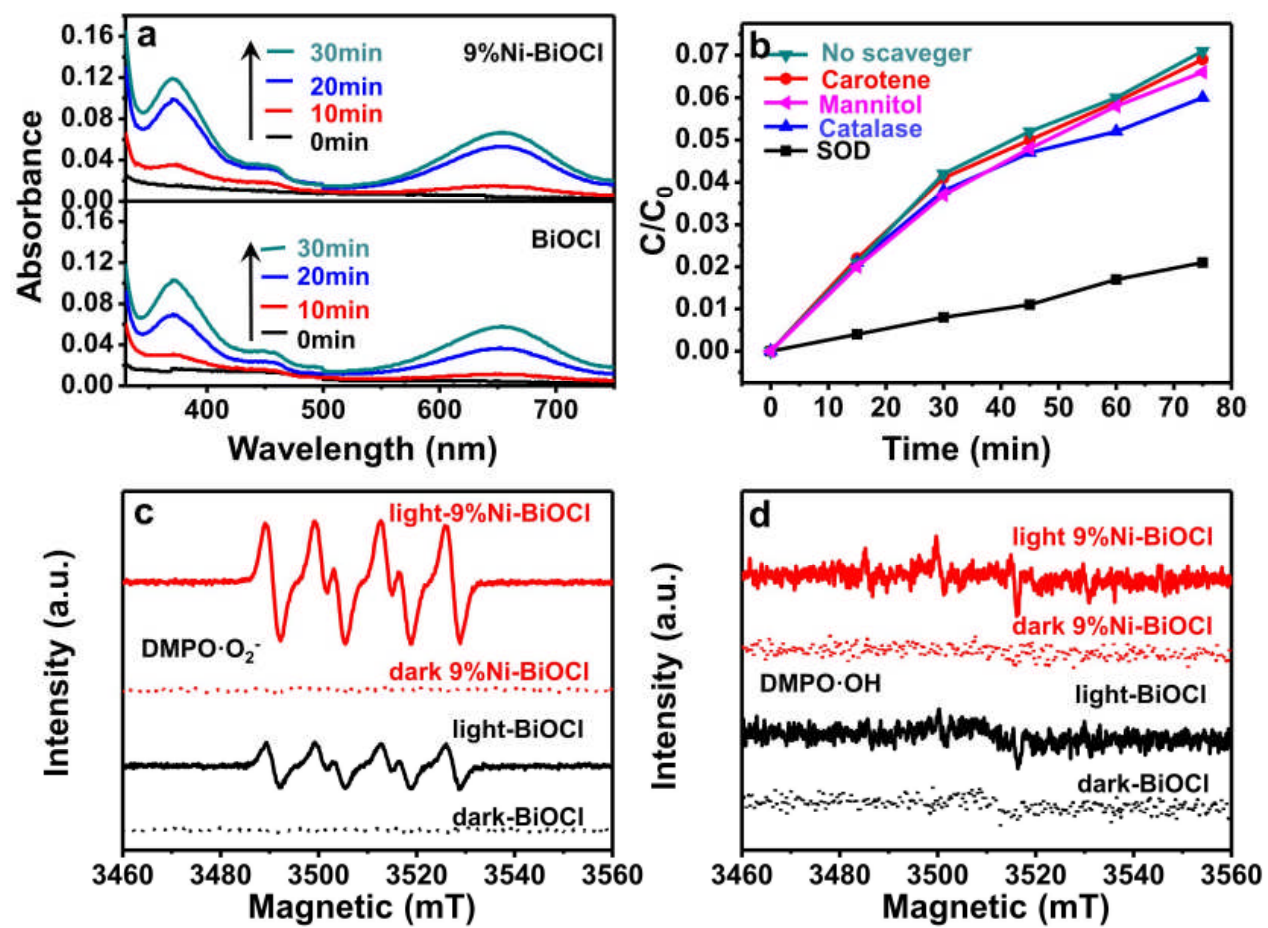

Fig. 4. (a) Absorption spectrum changed with time of 9\% $\mathrm{Ni}-\mathrm{BiOCl}$ and $\mathrm{BiOCl}$; (b) absorbance change over $9 \% \mathrm{Ni}-\mathrm{BiOCl}$ and $\mathrm{BiOCl}$ at $370 \mathrm{~nm}$ with three kind of scavengers; (c-d) ESR pattern of $9 \% \mathrm{Ni}-\mathrm{BiOCl}$ and $\mathrm{BiOCl}$ in the presence of $\mathrm{DMPO} \cdot \mathrm{O}_{2}{ }^{-}$and $\mathrm{DMPO} \cdot \mathrm{OH}$, respectively.

To demonstrate the ROS generation performance of the samples, oxygen activity examination was carried out. Fig. 4a showed that within 30 minutes, the activated oxygen scanning peak of $9 \% \mathrm{Ni}-\mathrm{BiOCl}$ was higher compared with $\mathrm{BiOCl}$, which illustrated that the amount of ROS produced by $9 \% \mathrm{Ni}-\mathrm{BiOCl}$ was more than $\mathrm{BiOCl}$ under visible light. Fig 4 b. showed that $\cdot \mathrm{OH},{ }^{1} \mathrm{O}_{2}$ and $\mathrm{H}_{2} \mathrm{O}_{2}$ played minor auxiliary role in photocatalysis while $\cdot \mathrm{O}_{2}^{-}$was the primary $\mathrm{ROS}$ in the photocatalytic process.

The ESR was adopted to further detect free radical intermediates generated on the surface of the catalyst when photocatalysis occurs. In Fig. 4c and Fig. 4d, no signal peaks were observed in the ESR spectra of the samlpes under dark conditions, indicating that visible light acted an vital effect for the generate of free radicals. In Fig. 
4c, the peaks of DMPO $\cdot \mathrm{O}_{2}{ }^{-}$of $9 \% \mathrm{Ni}-\mathrm{BiOCl}$ is obviously stronger than $\mathrm{BiOCl}$, indicating that $9 \% \mathrm{Ni}-\mathrm{BiOCl}$ generates more superoxide radicals in the reaction. The characteristic signal of DMPO-·OH adducts a four-line spectra which intensity ratio is 1:2:2:1, but there were no obvious characteristic peaks observed in Fig. 4d, indicating that the catalyst materials only produced a small amount of $\cdot \mathrm{OH}$. Above all, doping $\mathrm{Ni}$ can enhance the generation of $\cdot \mathrm{O}_{2}{ }^{-}$, and $\cdot \mathrm{O}_{2}{ }^{-}$is the most dynamic factor in photocatalytic process.

\subsection{Photocatalytic ROS generation mechanism}
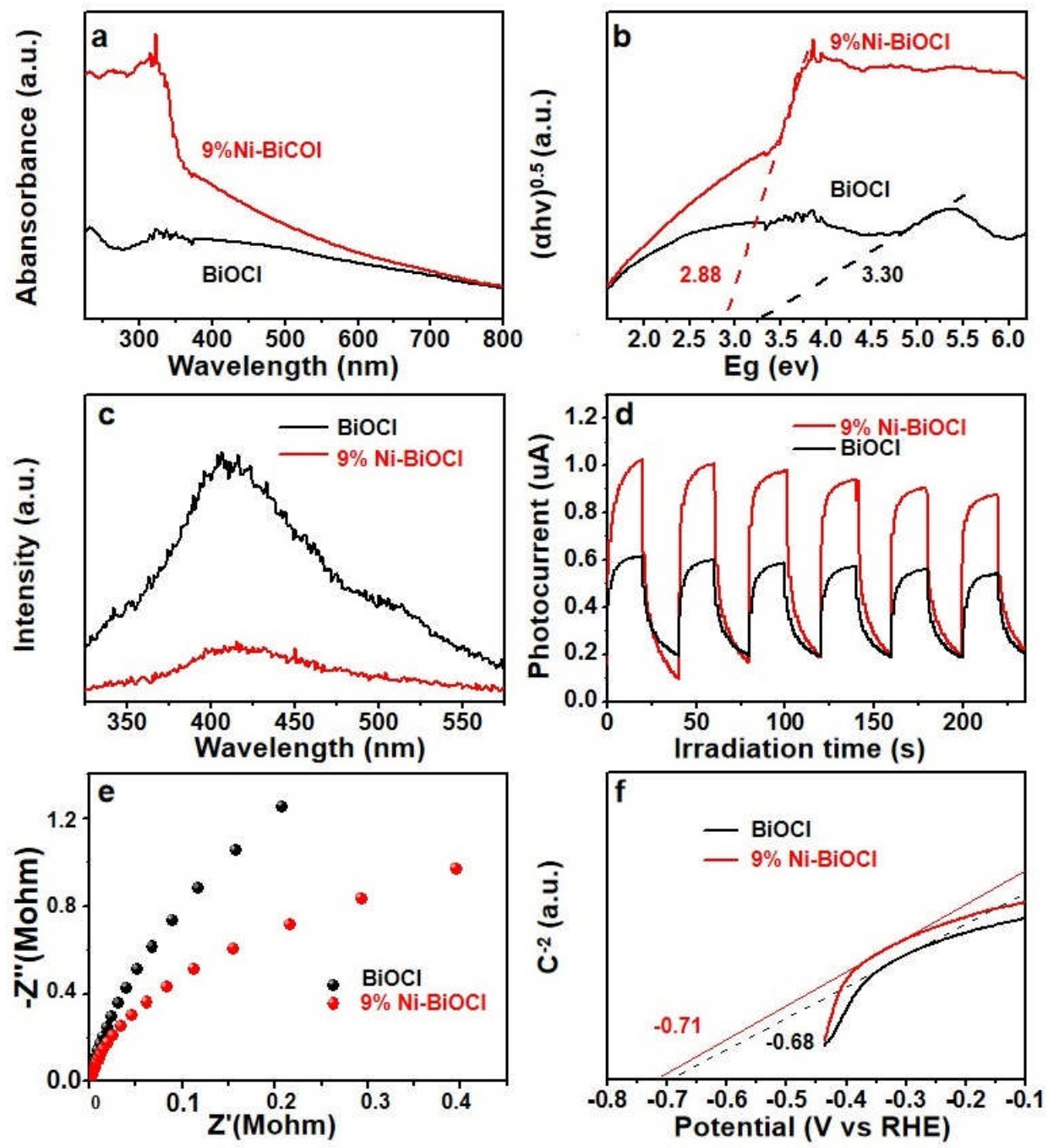
Fig. 5. (a) UV-vis diffuse spectra; (b) Tauc plot for band gap determination; (c) PL; (d) Transient photocurrent curves; (e) EIS spectra, and (f) MS plots of 9\% Ni-BiOCl and BiOCl.

The UV-vis-DRS technology was applied to research the band gap of the new catalyst and the optical response of the products. As shown in Fig. 5a, 9\% Ni-BiOCl has a broader absorption spectrum regions to ultraviolet and visible light compared with $\mathrm{BiOCl}$, and its absorption band edge is about $350 \mathrm{~nm}$. The calculated Tauc curve is shown in Fig. 5b, the band gap of a photocatalyst is predominated by the range of linearity above the light-absorbing edge. Therefore, the band-gap energies are $3.30 \mathrm{eV}$ and $2.88 \mathrm{eV}$ for $\mathrm{BiOCl}$ and $\mathrm{Ni}-\mathrm{BiOCl}$, respectively, which indicate that the doping of $\mathrm{Ni}$ reduce the band gap energy successfully and promote the separation of electron-hole.

For Photoluminescence (PL) curves (Fig. 5c), the fluorescence intensity of $\mathrm{Ni}-\mathrm{BiOCl}$ is evidently lower than $\mathrm{BiOCl}$, declaring that the carriers of $\mathrm{Ni}-\mathrm{BiOCl}$ have a lower recombination probability, and the lifetime of photogenerated carriers is longer. Previous studies have shown that metal ions doped into the catalyst lattice can effectively accept electrons, thereby generating more activated oxygen on the catalyst surface to improve photocatalytic performance [41]. Furthermore, Fig. 5d owned the same phenomenon, 9\% Ni-BiOCl nanosheets show a higher photocurrent response, and the current density is 1.5 times than that of $\mathrm{BiOCl}$, indicating that the doping of $\mathrm{Ni}$ make the $9 \% \mathrm{Ni}-\mathrm{BiOCl}$ a high-quality photosensitive. 
To further assess the charge of separation effectiveness of the $\mathrm{BiOCl}$ and $\mathrm{Ni}-\mathrm{BiOCl}$ samples, the EIS and MS spectra were measured. As shown in Fig. 5e, the radius of curvature of $\mathrm{Ni}-\mathrm{BiOCl}$ is lower than that of $\mathrm{BiOCl}$, indicating that photo-generated carriers in $9 \% \mathrm{Ni}-\mathrm{BiOCl}$ are easier to separate. In addition to this, the slope of the MS diagram could represent the innate charge carrier density $\left(\mathrm{N}_{\mathrm{d}}\right)$. Obviously, Ni-BiOCl possess more charge carriers.

As shown in Fig. 5f, the MS plot shows that the conduction band (CB) of $9 \%$ $\mathrm{Ni}-\mathrm{BiOCl}$ is $-0.71 \mathrm{eV}$, while the $\mathrm{CB}$ of $\mathrm{BiOCl}$ is $-0.68 \mathrm{eV}$, and the $\mathrm{CB}$ of $9 \% \mathrm{Ni}-\mathrm{BiOCl}$ is smaller than that of $\mathrm{BiOCl}$. Taking band gap energy into consideration, the valence band (VB) top positions of $9 \% \mathrm{Ni}-\mathrm{BiOCl}$ was computed as $+2.17 \mathrm{eV}$ while the $\mathrm{BiOCl}$ was $+2.62 \mathrm{eV}$. The Fig. S3 revealed that $\cdot \mathrm{OH}$ was produced by the $\mathrm{OH}^{-}$while $\cdot \mathrm{O}_{2}^{-}$ was produced by $\mathrm{O}_{2}$. In summary, the results showed that not only the band gap energy of $\mathrm{BiOCl}$ was shortened after $\mathrm{Ni}$ doping, but also the intrinsic charge carrier density and its transport effectiveness were improved.

\subsection{Photocatalytic degradation Rh B and BPA}



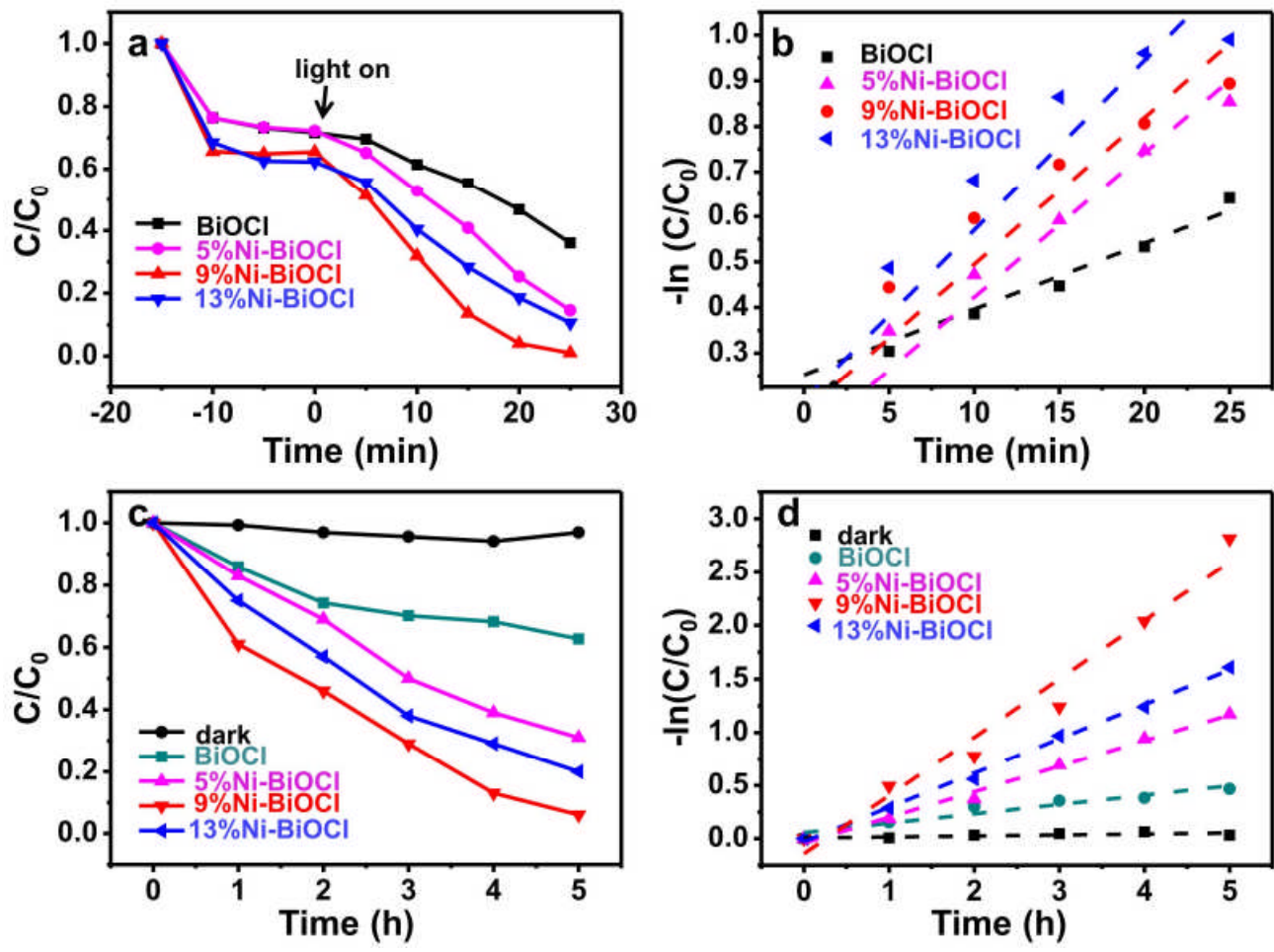

Fig. 6. (a) Photocatalytic degradation Rh B; (b) corresponding kinetic curves; (c) Photocatalytic degradation BPA curves; and (d) corresponding kinetic curves. (At room temperature, the concentration of $\mathrm{Rh} \mathrm{B}$ and $\mathrm{BPA}$ are $10 \mathrm{mg} / \mathrm{L}$ and the reaction solution was $15 \mathrm{~cm}$ away from the $300 \mathrm{~W}$ xenon lamp, and the rotating speed of the magnetic stirrer was $800 \mathrm{r} / \mathrm{min}$.

$\mathrm{Rh} \mathrm{B}$ and BPA were selected as the target pollutants to estimate the photocatalytic performance of Ni-BiOCl. The dark adsorption experiment of rhodamine B showed that the adsorption value almost reached the maximum after 5 minutes of dark reaction, during the next 10 minutes it decreased slightly, and after 15 minutes it reached the adsorption/desorption equilibrium completely (Fig. S4). As shown in Fig. 6a, after reaching adsorption-desorption equilibrium, $\mathrm{Rh} \mathrm{B}$ can be degraded at an alarming rate. The degradation rates of $\mathrm{BiOCl}, 5 \% \mathrm{Ni}-\mathrm{BiOCl}, 9 \% \mathrm{Ni}-\mathrm{BiOCl}$ and $13 \%$ $\mathrm{Ni}-\mathrm{BiOCl}$ were $63.98 \%, 85.36 \%, 98.97 \%$ and $89.38 \%$ under visible light for 25 minutes respectively. It is worth mentioning that in Fig. S5 the degradation rate of Rh 
B can still reach $90 \%$ after 5 repeated degradation experiments. There was no change in the peak position of the XRD pattern of the sample, but the peak was weakened. The results showed that the sample had good reusability and stability. $\mathrm{R}^{2}$ and Root mean square error (RMSE) are both statistical parameters that show the difference between the actual measured value and the model fitting curve. $\mathrm{R}^{2}$ is widely used to indicate the fitting accuracy of which values range from 0 to 1 and the higher of $\mathrm{R}^{2}$ the higher the more accurate of the model [42]. Relevant research shows that when the data is in the form of $\log _{10}$, if RMSE is less than 0.5 the model will be more accurate [43]. In Fig. 6b, the degradation of $\mathrm{Rh} \mathrm{B}$ met the quasi-first-order kinetic equation, because the kinetic fitting parameters $\mathrm{R}^{2}$ were all bigger than 0.9 and RMSE were less than 0.5 (Table. S1). The results of BPA degradation experiments were displayed in Fig. 6c, the dark adsorption capacity of the sample for BPA was very low under dark conditions. While under visible light, the degradation rates of BPA were $37 \%, 69 \%, 94 \%$, and $80 \%$ after 5 hours with doping amount of $0 \%, 5 \%, 9 \%$, and $13 \%$, respectively. And in Fig. 6d, the kinetic constants of $9 \% \mathrm{Ni}-\mathrm{BiOCl}$ is $\mathrm{BiOCl} 0.62$ times than that of $\mathrm{BiOCl}$ (Table. S2). Therefore, the results show that $9 \% \mathrm{Ni}-\mathrm{BiOCl}$ has the highest photocatalytic degradation ability. Compared with those reported in the literature at the similar operating conditions the $9 \% \mathrm{Ni}-\mathrm{BiOCl}$ nanosheets performed well to Rh B and BPA (Table. S8).

\subsection{Photocatalytic algae removal experiment}



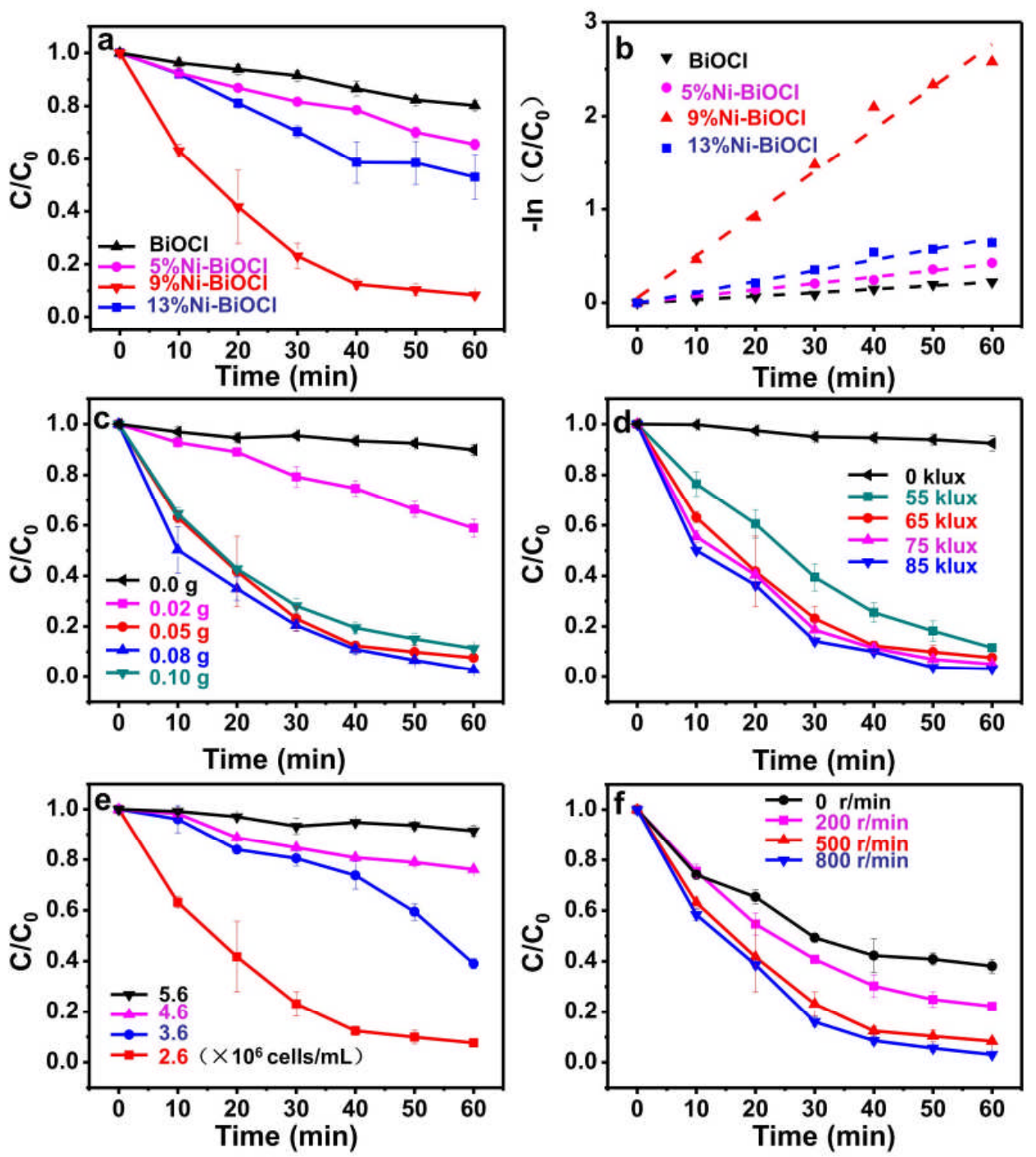

Fig. 7. (a) The effect of Ni doping on photocatalytic algae removal; (b) Kinetic fitting of the effect of doping amount on algae removal; The effects of (c) catalyst dosage; (d) light intensity; (e) algae concentration; and (f) rotation speed on photocatalytic algae removal. (Taken together, the optimum condition for the four parameters are $0.05 \mathrm{~g}$, $65 \mathrm{klux}, 2.6 \times 10^{6}$ cells $/ \mathrm{mL}, 500 \mathrm{r} / \mathrm{min}$. Except for variables, the others are the optimum condition in the above single factor experiments.)

Fig. 7a revealed the result of photocatalytic inactivation on $M$. aeruginosa employing $\mathrm{BiOCl}$ at different $\mathrm{Ni}$ doped percentage. After 60 minutes light irradiation, the algae inhibition rates of the experimental group of $\mathrm{Ni}-\mathrm{BiOCl}(5 \%, 9 \%, 13 \%)$ were $34.59 \%, 93.04 \%$ and $46.94 \%$, respectively, while the pure $\mathrm{BiOCl}$ changed little. As 
the Fig. $7 b$ shown, the rate of algae removal conformed to the quasi-first-order kinetic equation. And the algae removal rate of $9 \% \mathrm{Ni-BiOCl}$ was the fastest (Table. S3). Hence, $9 \% \mathrm{Ni}-\mathrm{BiOCl}$ was used for the following influencing factors study.

It can be seen form Fig. 7c, the photocatalytic inactivation effectiveness of $0.08 \mathrm{~g}$ at $2.6 \times 10^{6}$ cells $\mathrm{mL}^{-1}$ was the best. The reaction rate constants at the dosages indicated the $k$ value $0.08 \mathrm{~g}$ was $0.0573 \mathrm{~min}^{-1}$ slightly higher than $0.05 \mathrm{~g}$ (Table. S4). Hence, $0.05 \mathrm{~g}$ was selected as the vintage catalyst amount. It is worth mentioning that, when the dosage of the photocatalyst exceeds a certain value, the penetration depth of the photons decreases, thereby reduce the efficiency of the catalyst [44].

Another major element in the photodegradation process is the light intensity [45]. In Fig. 7d, with the increase of light intensity, the algae suppression rate was enhanced. Fig. S6b showed that the degradation rate constants were $0.0452 \mathrm{~min}^{-1}$, $0.0515 \mathrm{~min}^{-1}$ and $0.0605 \mathrm{~min}^{-1}$ at $65 \mathrm{klux}, 75 \mathrm{klux}$, and $85 \mathrm{klux}$, respectively (Table. S5). The gap among the three values is small, which is consistent with the intuitive results of Fig. S7. Considering energy saving, 65 klux was determined as the suitable response light intensity.

In addition, the initial density of algae liquid has a great influence on the algae inhibition rate. As shown in Fig. $7 \mathrm{e}$, when it is $2.6 \times 10^{6}$ cells $\mathrm{mL}^{-1}$, the algae removal rate was the highest and after visible light for 60 minutes it reached 93.04\%. Kinetic fitting results showed the same trend (Fig. S6c and Table. S6). These phenomena indicated that the best effect of algae removal is in the early logarithmic growth. 
Moreover, the speed of the magnetic stirrer is also a factor that cannot be ignored in this paper. As shown in Fig. 7f, the higher the speed, the greater the rate of algae suppression. This may be due to the increase of the dissolved oxygen in the water, which promotes the generation of ROS to improve algae removal rate [46]. The curve of dissolved oxygen with speed proves this view (Fig. S8 and Table. S7). The algae suppression rate at $800 \mathrm{rmin}^{-1}$ is almost the same as the algae suppression rate at 500 $\mathrm{r} \min ^{-1}$, so $500 \mathrm{r} \min ^{-1}$ was selected as the reaction speed for photocatalytic degradation. Comparing the performance of the studied $\mathrm{Ni}-\mathrm{BiOCl}$ nanosheets with those reported in the literature at the similar operating conditions, the $9 \% \mathrm{Ni}-\mathrm{BiOCl}$ had a better effect.for $M$. aeruginosa (Table. S8). 

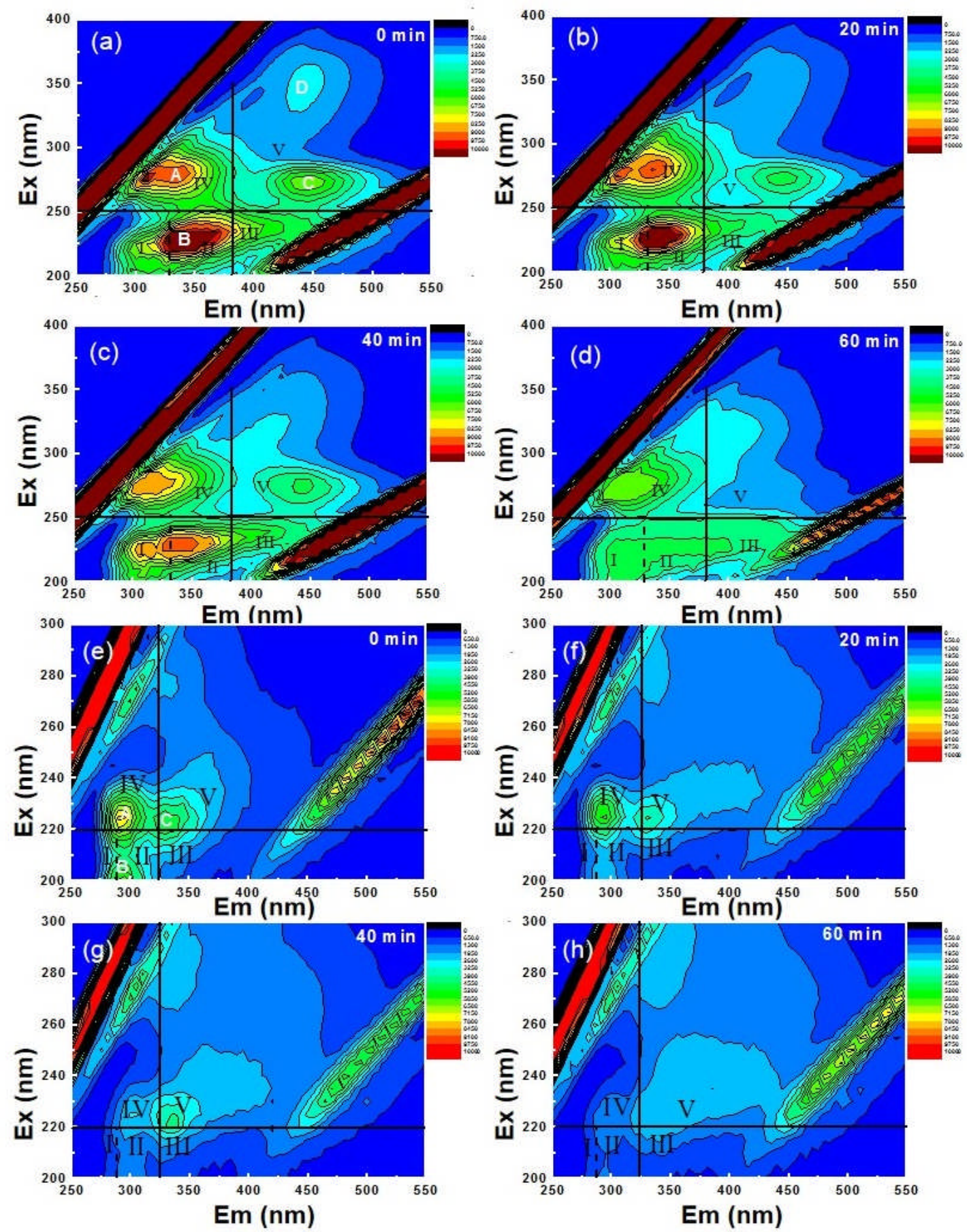

Fig. 8. The EEM of fluorescence spectra of IDOM (a-d) and EDOM (e-h).

Fig. 8(a-d) demonstrated the variety in fluorescence intensity at a regular time of 0 ,

20, 40 and 60 minutes with 9\% Ni-BiOCl. The IDOM (Intracellular dissolved organic matter) fluorescence spectra of the different response samples includes four peaks, which are defined as peak $\mathrm{A}(\mathrm{Ex} / \mathrm{Em}=280 / 330 \mathrm{~nm})$, peak $\mathrm{B}(\mathrm{Ex} / \mathrm{Em}=230 / 350 \mathrm{~nm})$, 
peak $C(E x / E m=280 / 480 \mathrm{~nm})$, and peak D $(E x / E m=350 / 430 \mathrm{~nm})$. The difference is that A represents microbial soluble metabolites, such as proteinoids, tryptophan, and tyrosine, and B represents aromatic proteins, such as tyrosine and BODs. And C and D are fulvic acid-like and humic acid-like fluorescence peaks, respectively [47]. After 20 minutes, the intensity of the four peaks decreased to varying degrees, indicating that some cells are damaged and inactivated, and the intracellular substances began to degrade. After 40 minutes, the peak $\mathrm{D}$ disappeared, and the colors of $\mathrm{A}, \mathrm{B}$ and $\mathrm{C}$ peaks became lighter, indicating that the intracellular proteinoids and humic acid produced by cell lysis continue to be degraded. The reduction of $\mathrm{A}$ and $\mathrm{B}$ peaks showed that $9 \% \mathrm{Ni}-\mathrm{BiOCl}$ causes algal cells irreversible death under visible light, because peaks $\mathrm{A}$ and $\mathrm{B}$ are indicators of biochemical organisms that reflect cell activity, peak C and peak D may originate from dead cells and organs when the reaction is carried out for 60 minutes, and the disappear of peaks $\mathrm{C}$ and $\mathrm{D}$ indicates the humus-like acid is mineralized and the dead cells are further degraded. To further study the changes in the process of algal cell degradation, the fluorescence response values of each region in the three-dimensional fluorescence spectra were calculated by the fluorescence region integration (FRI) means [48] (Fig. S9a). And the results of the fluorescence integral method calculation showed that the fluorescence intensity before and after the photocatalytic reaction was programmed from $149.8 \times 10^{7}$ to $74.4 \times 10^{7}$, indicating that the catalyst was able to achieve the degradation of organic substances produced in the manufacturing industry (Table. S9). 
There are two types of fluorescence peaks in the EEM of EDOM (Extracellular dissolved organic matter), including one protein-like fluorescence peak (A $\mathrm{Ex} / \mathrm{Em}=230 / 280 \mathrm{~nm})$, two humic acid-like fluorescence peaks $(\mathrm{B} \mathrm{Ex} / \mathrm{Em}=200 / 300 \mathrm{~nm}$, C Ex/Em=230/330 nm) (Fig. 8e-8h). As Fig. 8f shown, the fluorescence intensities of peaks $\mathrm{A}, \mathrm{B}$, and $\mathrm{C}$ were obviously weakened after 20 minutes. This is because the catalyst has degraded the extracellular and intracellular leakage of fluorescent active organic matter, and the effect is significant. After 40 minutes, peaks A and B gradually disappeared, while the fluorescence response of Peak $\mathrm{C}$ had been enhanced, indicating that organic matter represented by chlorophyll a, phycocyanin, and phycotoxin was gradually photocatalytic oxidized to humus-like substance. After 60 minutes irradiation, peaks A and B completely disappeared, and the Peak C had only a weak fluorescence response, indicating that the contents of the cells which were free of extracellular matter had been completely degraded, and the extracellular humic substance was almost completely degraded. According to the FRI histogram (Fig. $\mathrm{S} 9 \mathrm{~b}$ ), after 60 minutes, the total IDOM fluorescence response value decreased from $15.47 \times 10^{7}$ to $6.46 \times 10^{7}$ (Table. S10), which decreased by $58.24 \%$, indicating that the cells of $M$. aeruginosa are significantly inhibited and the active substances continued to decrease. 


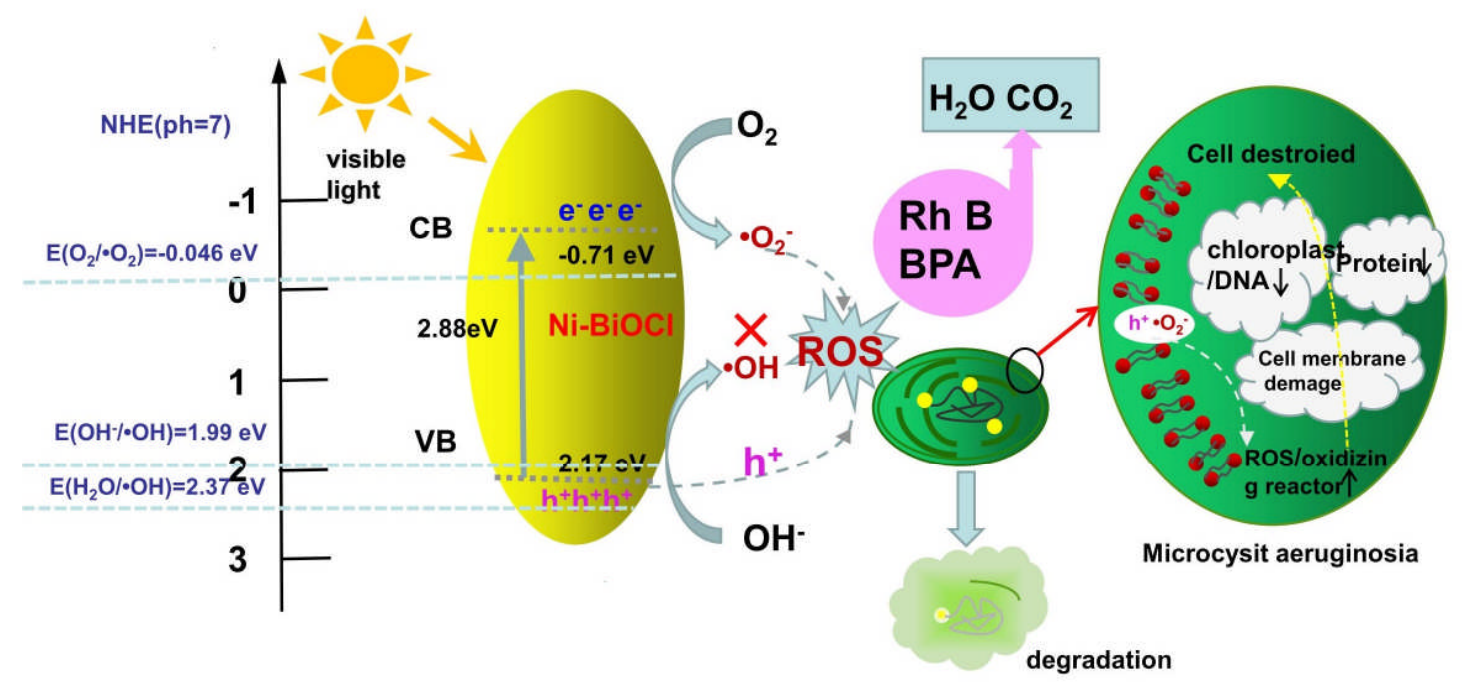

Fig. 9. A possible mechanism for photocatalytic degradation organics and $M$.

aeruginosia by $\mathrm{Ni}-\mathrm{BiOCl}$.

On basis of the above results, the mechanism of Ni-doped $\mathrm{BiOCl}$ photocatalytic degradation can be proposed. Ni doping improves the light absorption capacity, the density of photogenerated carriers, the separation efficiency of electron-hole pairs, and increases the oxygen vacancy of the material. Thereby the number of active species was increased. Capture agent experiments shown the active species in the degradation process are $\cdot \mathrm{O}_{2}^{-}$and $\mathrm{h}^{+}$, however, $\cdot \mathrm{O}_{2}^{-}$plays the major role (Fig. S10). Finally, in Fig. 9 the photocatalytic degradation of organics and M. aeruginosa can be described: $\mathrm{Ni}-\mathrm{BiOCl}$ is excited under visible light to generate photo-generated electron-hole pairs $\left(\mathrm{e}^{-}-\mathrm{h}^{+}\right)$and $\mathrm{e}^{-}$migrates from the valence band to the conduction band to react with $\mathrm{O}_{2}$ to generate superoxide radical $\left(\cdot \mathrm{O}_{2}^{-}\right)$. The organics can be mineralized to $\mathrm{CO}_{2}$ and $\mathrm{H}_{2} \mathrm{O}$. For $M$. aeruginosa, the cell wall can be destroyed by $\cdot \mathrm{O}_{2}^{-}$firstly, then the intracellular active fluorescent substance such as protein became inactivated, and the intracellular excretion such as chlorophyll and 
phycocyanin were further degraded to inorganic substances.

\section{Conclusions}

In this work, Ni-BiOCl was successfully prepared via a simple hydrothermal synthesis method without additional operations. Ni doping can efficiently extend photoabsorption and boost the separation electron-hole carries. Thus, Ni-BiOCl can generate more $\cdot \mathrm{O}_{2}{ }^{-}$than $\mathrm{BiOCl}$. Photodegradation experimental results indicated that 9\% Ni-BiOCl (mass percentage) showed excellent degradation performance for both inorganic and microorganisms under visible light irradiation. First, 9\% Ni-BiOCl showed efficient visible light photocatalytic degradation activity to Rh B and BPA. Secondly, Ni-BiOCl showed excellent inactivation of $M$. aeruginosa. And the mechanism was systematically studied. Results showed that $\cdot \mathrm{O}_{2}^{-}$played an irreplaceable role in the photocatalytic algae removal process and the cell can be degraded to inorganic substances. Furthermore, cycle experiment exhibited that $\mathrm{Ni}-\mathrm{BiOCl}$ had good recyclability and stability. This work provides excellent photocatalyst for waste water treatment.

\section{Acknowledgments}

The authors acknowledge financial support by the National Natural Science Foundation of China (NO.51779068), Open Foundation of State Key Laboratory of Mineral Processing BGRIMM-KJSKL-2019-20, and the Natural Science Foundation 
of Hebei Province (B2019202078).

\section{Conflict of interest}

The authors declare that they have no conflict of interest.

\section{References}

[1] C. Mu, Y. Zhang, W. Cui, Y. Liang, Y. Zhu, Removal of bisphenol A over a separation free 3D $\mathrm{Ag}_{3} \mathrm{PO}_{4}$-graphene hydrogel via an adsorption-photocatalysis synergy, Appl. Catal. B-Environ. 212 (2017) 41-49.

[2] A. Yeung, P. Agostino, A. Poljak, J. McDonald, M. Bligh, T. Waite, B. Neilan, Physiological and proteomic responses of continuous cultures of Microcystis aeruginosa PCC 7806 to changes in iron bioavailability and growth rate, Appl. Environ. Microbiol. 82 (2016) 5918-5929.

[3] K Elwakeel. Removal of Reactive Black 5 from aqueous solutions using magnetic chitosan resins[J]. J. Hazard. Mater. 167 (2009) 383-392.

[4] K. Park, S. Choi, S. Lee, J. Kweon, J. Song. Comparison of formation of disinfection by-products by chlorination and ozonation of wastewater effluents and their toxicity to Daphnia magna, Environ. Pollut. 215 (2016) 314-321.

[5] K Elwakeel, A Shahat, Z Khan, W Alshitari, E Guibal. Magnetic metal oxide-organic framework material for ultrasonic-assisted sorption of titan yellow and rose bengal from aqueous solutions, Chem. Eng. J. 392 (2020) 123635.

[6] X. Lei, T. Hong, W. Yao, Q. Wu, R. Zou, Hollow hydroxyapatite microspheres modified by CdS nanoparticles for efficiently photocatalytic degradation of tetracycline, J. Taiwan. Inst. Chem. E. $106(2020) 148-158$.

[7] K Elwakeel, A El-Bindary, A El-Sonbati, A Hawas. Magnetic alginate beads with high basic dye removal potential and excellent regeneration ability, Can. J. Chem. 95 (2017) 807-815.

[8] K Elwakeel, A Elgarahy, Z Khan, M Almughamisi, A Al-Bogami. Perspectives Regarding 
Metals/Minerals-Incorporated Materials for Water Purification: With Special Focus on $\mathrm{Cr}(\mathrm{VI})$ Removal, Mater. Adv. (2020) https://doi.org/10.1039/D0MA00153H.

[9] A. Mamaghani, F. Haghighat, C. Lee, Photocatalytic oxidation technology for indoor environment air purification: The state-of-the-art, Appl. Catal. B-Environ. 203 (2017) 247-269.

[10] C. Wang, Y. Zhang, W. Wang, D. Pei, G. Huang, J. Chen, X. Zhang, H. Yu, Enhanced photocatalytic degradation of bisphenol A by Co-doped $\mathrm{BiOCl}$ nanosheets under visible light irradiation, Appl. Catal. B-Environ. 221 (2018) 320-328.

[11] R. Jaiswal, N. Patel, A. Dashora, R. Fernandes, Efficient Co-B-codoped $\mathrm{TiO}_{2}$ photocatalyst for degradation of organic water pollutant under visible light, Appl. Catal. B-Environ. 183 (2016) $242-253$.

[12] J. Zhao, L. Wang, X. Yan, Y. Yang, Y. Lei, J. Zhou, Structure and photocatalytic activity of Ni-doped ZnO nanorods, Mater. Res. Bull. 46 (2011) 1207-1210.

[13] J. Sun, J. Song, M. Gondal, Preparation of $\mathrm{g}^{-} \mathrm{C}_{3} \mathrm{~N}_{4} / \mathrm{BiOX}(\mathrm{X}=\mathrm{Cl}, \mathrm{Br}$, I) composites, and their photocatalytic activity under visible light irradiation, Res. Chem. Interm. 41 (2015) 6941-6955.

[14] M Novokreshchenova, Y Yukhin, B Bokhonov. Highly Pure Bismuth(III) Oxochloride Synthesis, Chem. Sustain. Dev. 13 (2005) 563-568.

[15] M. Gao, D. Zhang, X. Pu, H. Li, W. Li, X. Shao, D. Lv, B. Zhang, J. Dou. Combustion synthesis of Fe-doped BiOCl with high visible light photocatalytic activities, Sep. Purif. Technol. 162 (2016) 114-119.

[16] M Liu, L Zheng, G Lin, L Ni, X Song. Synthesis and photocatalytic activity of $\mathrm{BiOCl} /$ diatomite composite photocatalysts: Natural porous diatomite as photocatalyst support and dominant facets regulator, Adv. Powder. Technol. 31 (2020) 339-350.

[17] M. Tarip, Y. Li, W. Li, Z. Zhang, Y. Hu, M. Zhu, H. Jin, Y.B. Li, K. Skotnicova, Ferromagnetic coupling of Fe3+-VO-Fe3+polarons in Fe-doped ZnO, Ceram. Int. 44 (2018) $71-75$.

[18] C. Mao, H. Cheng, H. Tian, H. Li, L. Zhang, Visible Light Driven Selective Oxidation of Amines to Imines with BiOCl: Does Oxygen Vacancy Concentration Matter, Appl. Catal. B-Environ. 228 (2018) 87-96. 
[19] C. Liu, L. Zou, L. Wang, H. Zhang, Z. Zhang, $\mathrm{MoS}_{2}$ nanosheets vertically grown on RGO by a liquid phase epitaxial method and its visible light photocatalytic properties, J. Mater. Sci. 55 (2020) 6915-6927.

[20] L Wang, J Liu, T Tang, N Xie, F Sun. The optimization of the doping level of boron, silicon and nitrogen doped diamond film on Co-cemented tungsten carbide inserts. Phys. B Condens. Matter. 550 (2018) 280-293

[21] P Pascariu, I Tudose, M Suchea, E Koudoumas, N Fifere, A Airinei. Preparation and characterization of $\mathrm{Ni}$, Co doped $\mathrm{ZnO}$ nanoparticles for photocatalytic applications. Appl. Surf. Sci. 448 (2018) 481-488.

[22] Q Gao, Y Dai, B Han, W Zhu, X Li, C Li. Enhanced gas-sensitivity and ferromagnetism performances by the Ni-doping induced oxygen vacancies in $(\mathrm{Mn}, \mathrm{Ni}$ ) codoped $\mathrm{ZnO}$ nanorods. Appl. Surf. Sci. 409 (2019) 178-187.

[23] Y. Mi, L. Wen, D. Cao, R. Xu, Y. Fang, Y. Zhou, Y. Lei, Fe(III) modified BiOCl ultrathin nanosheet towards high-efficient visible-light photocatalyst, Nano. Energy. 30 (2016) 109-117.

[24] V. Bhati, S. Ranwa, M. Fanettif, M. Valant, M. Kumar, Efficient hydrogen sensor based on Ni-doped ZnO nanostructures by RF sputtering, Actuat. B-Chem. 255 (2017) 588-597.

[25] A. Kumar, P. Kumar, C. Joshi, M. Manchanda, R. Boukherroub, S. Jain, Nickel Decorated on Phosphorous-Doped Carbon Nitride as an Efficient Photocatalyst for Reduction of Nitrobenzenes, Nanomaterials. 6 (2016) 59-72.

[26] C. Feng, Z. Chen, J. Jing, J. Hou, J. Mater, The photocatalytic phenol degradation mechanism of Ag-modified ZnO nanorods, Chem. C. 8 (2020) 3000-3009.

[27] F. Chen, Q. Yang, X. Li, et al, Hierarchical assembly of graphene-bridged $\mathrm{Ag}_{3} \mathrm{PO}_{4} / \mathrm{Ag} / \mathrm{BiVO}_{4}$ (040) Z-scheme photocatalyst: An efficient, sustainable and heterogeneous catalyst with enhanced visible-light photoactivity towards tetracycline degradation under visible, Appl. Catal. B-Environ. 200 (2016) 330-342.

[28] H. Wang, J. Li, P. Huo, Y. Yan, Q. Guan, Preparation of $\mathrm{Ag}_{2} \mathrm{O} / \mathrm{Ag}_{2} \mathrm{CO}_{3} / \mathrm{MWNTs}$ composite photocatalysts for enhancement of ciprofloxacin degradation, Appl. Surf. Sci. 366 (2015) 1-8.

[29] A. Serrà, P. Pipabc, E. Gómezde, L. Philippea, Efficient magnetic hybrid ZnO-based photocatalysts for visible-light-driven removal of toxic cyanobacteria blooms and cyanotoxins, 
Appl. Catal. B-Environ. 268 (2020) 118745.

[30] A. Tolbin, V. Pushkarev, L. Tomilova, N. Zefirov, Threshold concentration in the nonlinear absorbance law, Phys. Chem. Chem. Phys. 19 (2017) 12953-12958.

[31] H. Chen, X. Yu, Y. Zhu, X. Fu, Y. Zhang, Controlled synthesis of $\{001\}$ facets-dominated dye-sensitized $\mathrm{BiOCl}$ with high photocatalytic efficiency under visible-light irradiation, J. Nanopart. Res. 18 (2016) 225-237.

[32] R. Shannon, Revised effective ionic radii and systematic studies of interatomic distances in halides and chalcogenides, Acta. Crystallogr. 32 (1976) 751-67.

[33] B Chouchene, T Chaabane, L Balan, E Girot, K Mozet, G Medjahdi, R Schneider. High performance Ce-doped $\mathrm{ZnO}$ nanorods for sunlight-driven photocatalysis, Beilstein. J. Nanotechnol. 7 (2016) 1338-1349.

[34] A. Dakhel, Hydrogen influenced the structural and optical properties of Ni-doped BiOCl nanocomposite: creation of FM properties, Appl. Phys. A. 125 (2019) 89-95.

[35] R. Tanwar, B. Kaur, M. Kumar, Highly efficient and visible light driven Ni0.5 Zn0.5 $\mathrm{Fe}_{2} \mathrm{O}_{4} @$ PANI modified BiOCl heterocomposite catalyst for water remediation, Appl. Catal. B-Environ. 211 (2017) 305-322.

[36] C. Wang, X. Zhang, H. Qiu, X. Gui, Q. Han, $\mathrm{Bi}_{24} \mathrm{O}_{31} \mathrm{Br}_{10}$ nanosheets with controllable thickness for visible-light-driven catalytic degradation of tetracycline hydrochloride, Appl. Catal. B-Envirn. 205 (2017) 615-623.

[37] H. Gnayem, Y. Sasson, Nanostructured 3D Sunflower-like Bismuth Doped BiOClxBr1-x Solid Solutions with Enhanced Visible Light Photocatalytic Activity as a Remarkably Efficient Technology for Water Purification, J. Phys. Chem. C. 119 (2015) 19201-19209.

[38] J. Xia, L. Xu, J. Zhang, S. Yin, H. Li, H. Xu, J. Di, Improved visible light photocatalytic properties of $\mathrm{Fe} / \mathrm{BiOCl}$ microspheres synthesized via self-doped reactable ionic liquids, Cryst. Eng. Comm. 15 (2013) 10132-10141.

[39] H. Li, J. Shang, Z. Ai, L. Zhang, Efficient Visible Light Nitrogen Fixation with BiOBr Nanosheets of Oxygen Vacancies on the Exposed \{001\} Facets, J. Am. Chem. Soc. 317 (2015) 6393-6399. 
[40] Q. Wang, W. Wang, L. Zhong, D. Liu, X. Gao, F. Gui, Oxygen vacancy-rich 2D/2D BiOCl-g- $\mathrm{C}_{3} \mathrm{~N}_{4}$ ultrathin heterostructure nanosheets for enhanced visible-light-driven photocatalytic activity in environmental remediation, Appl Catal B-Environ 220 (2018) 290-302.

[41] S. Jin, F. Shiraishi, Photocatalytic activities enhanced for decompositions of organic compounds over metal-photodepositing titanium dioxide, Chem. Eng. J. 97 (2004) 203-211.

[42] E Carona, G Chevrefils, B Barbeaua, P Paymentb, M Prévosta. Impact of microparticles on UV disinfection of indigenous aerobic spores, Water. Res. 41 (2007) 4546-4556.

[43] A Geeraerd, V Valdramidis, J Impe. GInaFiT, a freeware tool to assess non-log-linear microbial survivor curves, In. J. Food. Microbiol. 102 (2005) 95-105.

[44] Z. He, Y. Shi, C. Gao, L. Wen, S. Son, BiOCl/BiVO 4 p-n Heterojunction with Enhanced Photocatalytic Activity under Visible-Light Irradiation, J. Phys. Chem. C. 118 (2013) 389-398.

[45] Y. Horie, D. David, M. Taya, S. Tone, Effects of Light Intensity and Titanium Dioxide Concentration on Photocatalytic Sterilization Rates of Microbial Cells, Ind. Eng. Chem. Res. 35 (1996) 3920-3926.

[46] T. Hirakawa, T. Daimon, M. Kitazawa, N. Ohguir, C. Koga, N. Negishi, An approach to estimating photocatalytic activity of $\mathrm{TiO}_{2}$ suspension by monitoring dissolved oxygen and superoxide ion on decomposing organic compounds, J. Photoch. Photobio. A. 190 (2007) 58-68.

[47] H. Wang, R. Zhao, M. Zhou, C. Guo, Y. Liu, S. Jiang, Preparation of polyclonal antibody highly specific for mouse BRD7 protein and its application, Acta. Bioch. Bioph. Sin. 46 (2014) $163-166$.

[48] W. Chen, P. Westerhoff, J. Leenheer, K. Booksh, Fluorescence Excitation Emission Matrix Regional Integration to Quantify Spectra for Dissolved Organic Matter, EST. 37 (2003) $5701-5710$. 